\title{
Democracia, ativismo e modernidade radicalizada na América Latina
}

\author{
Marco Aurélio Nogueira \\ UNESP, Sao Paulo, Brasil. Email: nogueira@fclar.unesp.br
}

\begin{abstract}
Resumo: O texto procura analisar três desafios impostos pela modernidade radicalizada à democracia política: a disposição participativa, as pressões identitárias e a individualização. Impulsionadas pelas mudanças trazidas pela dinâmica dessa modernização, as sociedades se fragmentam mais e suas partes (grupos, indivíduos, regiões) passam a seguir lógicas próprias - ainda que, paradoxalmente, tudo fique mais conectado. Novos sujeitos e novas formas de ativismo geram mais conflitos, mas não conseguem redirecionar o jogo político em termos emancipadores. A hiperatividade da sociedade civil ocorre mais em função da necessidade de autoexpressão que da disposição para organizar consensos. A “zona de ação política” que assim desponta é menos institucional e mais individualizada, mais flutuante e menos estruturada.
\end{abstract}

Palavras-chave: modernidade radicalizada, democracia política, individualização, ativismo, identidades, participação, sociedade civil.

\section{Democracia, activismo y modernidad radicalizada en América Latina}

Resumen: El artículo analiza tres retos que plantea la modernidad radicalizada a la democracia política: disposición participativa, presiones identitarias e individualización. Impulsadas por los cambios producidos por la dinámica de esta modernización, las sociedades se fragmentan más y sus partes (grupos, individuos, regiones) pasan a seguir sus propias lógicas -aunque, paradójicamente, todo está más conectado. Nuevos sujetos y nuevas formas de activismo generan más conflictos, pero no pueden redirigir el juego político en términos de emancipación. La hiperactividad de la sociedad civil se debe más a la necesidad de autoexpresión que a la disposición para construir consensos. La "zona de acción política" que así surge es menos institucional y más individualizada, más fluctuante y menos estructurada.

Palabras clave: modernidad radicalizada, democracia política, individualización, activismo, identidades, participación, sociedad civil.

\section{Democracy, activism and radical modernity in Latin America}

\begin{abstract}
The paper analyzes three challenges posed by radicalized modernity to political democracy: participatory disposition, identity pressures and individualization. Driven by changes brought about by the dynamics of this modernization, societies are more fragmented and its parts (groups , individuals , regions ) are following their own logic -even though, paradoxically, everything is more connected. New subjects and new forms of activism generate more conflicts but cannot redirect the political game in emancipatory terms. The hyperactivity of
\end{abstract}


civil society is more due to the need for self-expression than the willingness to organize consensus. The "action zone policy" that thus emerges is less institutional and more individualized, more buoyant and less structured .

Keywords: radical modernity, political democracy, individualization, activism, identities, participation, civil society.

Observada da perspectiva do sul do mundo, e particularmente da América Latina, a democratização contemporânea processa-se em sociedades que conhecem forte reconfiguração.

Essas sociedades estão a se tornar inteiramente capitalistas, seja em termos estruturais, seja em termos superestruturais, quer dizer, como modo de produção e como cultura. O que havia de "vida tradicional” é recomposto, o que significa dizer que ou é dissolvido, ou é subordinado e descaracterizado, ou épreservado com outras significações. A partir de agora, a vida moderna e capitalista dialoga e contrasta somente consigo própria: torna-se reflexiva (Beck).

Nas sociedades periféricas, como são as da América Latina e do Caribe, em que a modernidade está deslocada de seus epicentros clássicos e desfocada do projeto moderno original, ergue-se, sobre uma ampla base de pobreza, exclusão e marginalidade, uma "segunda sociedade" de opulência seletiva, de inovação tecnológica, de redes e comunicação intensiva, de sistemas midiáticos sofisticados que, aos poucos, toma conta da "primeira sociedade", submetendo-a funcional e ideologicamente e passando a modelá-la. Nessas sociedades, a modernidade reflexiva, a hipermodernidade, a modernidade radicalizada, é periférica não porque se afirme um tempo depois dos países centrais, que as subordinam e exploram, nem porque avance em regiões geograficamente distintas, mas sim porque se objetiva tendo de processar um legado "colonial-autoritário" que obriga tais sociedades a conviver com bases sociais ainda mais explosivas e dilaceradas. A interpenetração de hipermodernidade e legado "colonial-autoritário" estão na base da dimensão particularmente dramática das sociedades periféricas.

As sociedades se globalizam porque aprofundam sua inserção no mercado mundial e porque passam a compartilhar - de modo certamente diferenciado e perverso -os traços principais que caracterizam nossa época: a mundialização das relações sociais, econômicas e políticas, a interconexão global, a frenética mobilidade dos capitais, a financeirização e a transnacionalização das economias, a segmentação e a expansão da oferta de produtos, a diluição relativa das fronteiras e dos territórios, a perda de soberania por parte dos Estados, a irresponsabilidade dos mercados, a crise da regulação e dos mecanismos de financiamento do setor público - traços que podem serassociados a um quadro nacional e internacional de turbulência, imprevisibilidade e "descontrole".

Não estamos, portanto, em uma simples fase de mundialização do 
capital, mas diante de um fenômeno mais profundo, capaz de convulsionar e alterar os eixos constitutivos da mentalidade coletiva e do agir social: a globalização mostra-se como uma verdadeira revolução temporal-espacialsocial, que modifica e influencia de modo expressivo a organização social e a vida cotidiana. Em boa medida, o que chamamos de globalização pode ser traduzido como sendo a revolução passiva (Gramsci) dos dias atuais, um processo vigoroso de mudanças que modifica os diversos equilíbrios entre espaço e tempo, território e sociedade, grupos e indivíduos mas que não se caracteriza por apresentar taxas particularmente expressivas de protagonismo político. Tal revolução insidiosa abala a organização social, o modo de vida e o conjunto da política, promovendo deslocamentos acentuados nas interações entre Estado e sociedade, entre Estado e Estado (relações internacionais), bem como sacrificando as diferentes formas de subjetividade.Não têm um autor, um sujeito, que se possa reconhecer. Apesar de haver uma revolução em marcha, nenhuma revolução propriamente politica ocorre.

Impulsionadas por essa dinâmica, as sociedades se fragmentam, se individualizam e perdem instituições: passam a carecer de "centros" de coordenação e articulação, vêem suas partes se afastarem umas das outras e seguirem lógicas próprias - ainda que, paradoxalmente, tudo fique mais conectado. Uma multidão de novos sujeitos agita-se e gera novas contradições, embora não consiga interferir de fato no jogo político e redirecioná-lo em termos emancipadores. O revigoramento e a hiperatividade da sociedade civil ocorrem mais em função das dinâmicas do mercado que da perspectiva do Estado, mais em função da luta de interesses que da luta de opiniões, mais como decorrência da competição que da busca de "sínteses políticas”. O risco de fragmentação corporativista da representação política aumenta, com efeitos deletérios sobre o processo político: partidos e governos se tornam mais “dependentes" dos vínculos com os interesses particulares que estão em sua base, e com isso perdem potência como representantes do "todo" e ficam menos ágeis no processo de tomada de decisões.

Isso significa que as sociedades se hiperpolitizam (tudo se torna disputa e controvérsia) e paradoxalmente se “despolitizam”, tanto no sentido de que passam a desconfiar de seus políticos, de suas instituições e dos procedimentos seguidos em termos de processo decisório, quanto no sentido de que se dessolidarizam do Estado. Sociedades, indivíduos, povos, nações e Estados tornam-se partes soltas de um conjunto que não mais apresenta articulação e equilíbrio sistêmico.

Mantém-se ativa, no entanto, uma expectativa social de proteção e operosidade estatal, vinda sobretudo de setores marginalizados e de uma classe média que, em parte expandida pela incorporação de expressivos contingentes populacionais beneficiados por programas governamentais e em parte empobrecida pelo desemprego e por políticas de ajuste, afirma seus direitos perante o Estado. Trata-se de uma expectativa que se articula, por um lado, com uma exigência difusa de que os governantes "decidam e 
façam" (vetor que impulsiona tendências populistas e de hipertrofia do Executivo) e, por outro, com uma crescente dificuldade para que se aceitem “ordens” que não nasçam de alguma modalidade de consulta ou interação. Pouco importa que essa interação seja meramente simbólica ou que os mecanismos deliberativos adotados produzam resultados precários e não sejam suficientes para vincular grupos, indivíduos e instituições: a questão não é tanto de alcançar novos consensos ou novos processos decisórios, mas sim de manifestar indignação, carências, desejos e opiniões.

Aumenta assim, paradoxalmente, a disposição social para instituir uma nova "zona de ação política”, menos institucional e mais subjetiva (individualista), de movimentação contínua, de pressões antissistêmicas difusas, erráticas, viabilizadas pelas maiores facilidades de comunicação e contato. Tal disposição social compensa a "despolitização”, na medida em que propõe uma politização diversa, de outra natureza, cujo teor ainda está por ser estabelecido. O agir societal, na verdade, se avoluma tendo como motor a afirmação de interesses segmentados, não a construção de novos consensos, de novas "sínteses políticas” ou de novas correlações políticas. Impulsiona uma nova modalidade de politização, mas não a institui plenamente.

Nesse contexto, a ação governamental perde força e legitimidade, até mesmo porque cai prisioneira de uma armadilha sistêmica e passa a produzir poucos resultados: Estados e governos ficam duplamente acossados pela economia internacionalizada, que não podem controlar, e pelas demandas e pressões internas, que não podem refrear nem atender de modo pleno. Os governos deixam de poder agir de modo unilateral e decisionista, têm de "ouvir mais", negociar mais e assimilar a disposição social que se anuncia, algumas vezes pondo-se a serviço dela e outras vezes dialogando com ela e incorporando-a a suas políticas. Muito do sucesso do ideal de democracia participativa expressa essa nova forma social - uma nova estrutura de ação -, além de repercutir uma nova plataforma ética, uma nova cultura de direitos e a força adquirida no plano da administração pública e do mundo empresarial pela idéia de gestão participativa.

Em decorrência, aprofunda-se o divórcio entre Estado e sociedade, entre partidos e cidadãos, entre classe política e população. Donde os políticos (os governantes, os partidos) ficarem cada vez mais distantes dos fins superiores da política - a realização do "bem comum” - e cada vez mais enredados em seus meios, sejam eles a violência, a disputa eleitoral, a gestão orçamentária ou a manipulação dos recursos de poder. Cresce o risco de inoperância e de corrupção, diminui a densidade ética da política. Uma complicada crise vai-se assim encorpando, a sugerir a imagem de "irrelevância" da política. Agredida e desajustada pelos novos termos da vida social, a política instituída passa a produzir mais problemas que soluções, inserindose num círculo de desgaste e deslegitimação. Deixa de ser um fator de composição social e de estabelecimento de equilíbrios e consensos. 
Podemos afirmar, assim, que as mudanças e os desenvolvimentos registrados nas sociedades atuais e nos relacionamentos entre seus integrantes - bem como em seu funcionamento institucional -são “a conseqüência de efeitos colaterais de uma primeira modernidade radicalizada”. Não provêm de um processo político, de uma revolução consciente ou de decisões deliberadas, mas são "impelidos pela dinâmica daqueles efeitos", que, ao se combinarem entre si, "geram uma situação para a qual não estamos de modo algum preparados": representam uma "alteração dos fundamentos" da vida social, uma "mudança de paradigma que nos obriga a desenvolver novos conceitos no âmbito das ciências sociais, como também novas instituições sociais e políticas”. (Beck, 2001: 24-25). Outro "social” emerge. Não se assiste à implosão de todas as categorias sociais ou daquilo que se costuma chamar de tecido coletivo, com a completa falência das "agências de socialização", como se afirmou certa vez (Touraine, 2006: 10). O que ocorre é a progressiva constituição de uma ordem social pós-nacional, multicêntrica, extremamente dinâmica e menos coesa, que repõe sobre novas bases as relações e as fronteiras entre classes, as estruturas de poder, o jogo política e a dinâmica cultural.

Isso atinge de modo frontal a política: esvazia suas instituições, torna suas regras menos vinculantes, confunde seus atores e, acima de tudo, modifica práticas, procedimentos, concepções e critérios de organização e deliberação. A política converte-se em gestão de interesses e os políticos em gestores, quase sempre impotentes para transformar as coisas ou dirigir as sociedades. Passa-se a ter outra ideia de governo: ou ele é visto como a encarnação "messiânica” das carências e angústias populares, ou como cúpula gerencial revestida de vontade e racionalidade próprias, vocacionada para administrar recursos, e que teria tanto mais êxito quanto mais se mostrasse equilibrada, responsável e tecnicamente focada. Com a prevalência da eficiência, desloca-se o peso das utopias e das operações de "transcendência” política. Passa a existir mais incentivo para que cada um (grupo ou pessoa) encontre em si mesmo as fontes e os parâmetros de sua identidade e de sua satisfação, ou então para que transfira essa tarefa para técnicos e especialistas. Diminui a disposição social para compor os interesses particulares vis-à-vis um interesse coletivo. Esforços de construção hegemônica (ou contra-hegemônica) tornam-se menos produtivos.

A própria oposição ao Estado ou ao "sistema" arrefece, cedendo espaço para modalidades negociadas de gestão compartilhada ou de ações afirmativas. Os movimentos sociais alternativos encontram seu sucedâneo nas organizações não-governamentais. Parte do que era dever do Estado converte-se em "responsabilidade social" e "voluntariado".

O território da política é assim ajustado. Particularmente no caso dos partidos mais à esquerda, reformadores, assiste-se à sua progressiva conversão ao "sistema”, ou seja, à redução de sua pujança contestadora e reformista. Tornam-se mais preocupados em gerir recursos de poder e maximizar seus próprios interesses eleitorais, desinteressando-se de agir 
para organizar novas hegemonias ou novos consensos e consentimentos. Para complicar, essa acomodação dos partidos ao poder não se faz de modo qualificado, mas a partir de uma concepção pequena de representação política (mais próxima da idéia de "mandato vinculado" que de "síntese política”) e reiterando práticas e procedimentos de natureza fisiológica, o que impossibilita que sua chegada ao vértice estatal represente um seu melhor posicionamento perante a sociedade. Em vez de se tornarem "fundadores de novos Estados” (Gramsci), convertem-se em operadores passivos de rotinas e estruturas estatais envelhecidas, com a agravante de que, agora, não podem mais contar com um Estado "soberano” e dotado de grande capacidade de regulação e empreendimento.

\section{Impactos e repercussoes na democracia politica}

Precisamos voltar a pensar nas determinações materiais da democracia. A modernidade radicalizada está impondo novos desafios a ela: de certo modo a desconstrói e subverte, dificultando seu funcionamento e o cumprimento de suas promessas, para fazer uso de uma idéia cara a Bobbio. Ao mesmo tempo, porém, força-a a buscar novos significados e novos procedimentos, a se ampliar e a se abrir para outros sujeitos.

A fase é de transição profunda, na qual aquilo que funcionava como vetor de estruturação da vida (material e espiritual) já não funciona mais. Justamente por isso, do mesmo modo que assistimos à exacerbação de tendências mesquinhas, egoístas, desumanizadoras, vemos crescer, pelo outro lado, manifestações de uma nova etapa civilizatória, mais rica em direitos, espaços e possibilidades. Os próprios ruídos da democracia realmente existente, ainda que muitas vezes de baixa frequência, acabam por abrir áreas renovadas de vida democrática, de contestação e de projeto.

Dentre os desafios que se impõem à democracia política - ameaçandoa, perturbando-a, renovando-a -é possível destacar três.

(a) O primeiro deles tem a ver com a disposição participativa, revelada ora como defesa de interesses e direitos, ora como postulação de melhores espaços de interferência e deliberação, ora como manifestação de vontade cívica de lutar por uma “boa sociedade”. Evidentemente, tal disposição colide de modo mais ou menos frontal com a centralidade da representação no edifício democrático e acentua o contraste entre vida social (individual) e vida política, ou, para falar de outro modo, entre a "política dos cidadãos", focada na vida, e a "política dos políticos", focada no poder. (Nogueira, 2005). A democracia e a liberdade transformam-se em ação e em vida cotidiana, impondo novas dinâmicas e novos problemas, que em boa medida ultrapassam os cânones e os ritos tradicionais da democracia: passa-se a viver em "condições de uma democracia interiorizada, com respeito àqual muitos conceitos e muitas receitas da primeira modernidade ficam inadequados"; em decorrência, surge e se expande uma refutação - muitas vezes bastante política - da política por parte dos cidadãos, e sobretudo 
dos jovens (Beck, 2000: 41-43).Deriva daí uma espécie de “desconstrução” da democracia representativa, que -por limites seus e por imposições da realidade -, vê crescer sua dificuldade de funcionar como mecanismo de processamento mais equilibrado das demandas e dos interesses, como fator de composição social, de conversão do particular em geral e de explicitação dialógica das diferenças.

A disposição participativa também sugere que não é propriamente a política que está em xeque, sem consensos e com pouca legitimidade. O que falha é a política instituída e institucionalizada - os sistemas, as regras, a organização da democracia, as leis, os partidos. A política como atividade dos cidadãos - como luta por direitos, como interesse cívico, vontade de participar e interferir na tomada de decisões, como preocupação com a vida comum e a boa sociedade -, essa não padece do mesmo mal, nem se ressente de falta de prestígio, embora esteja despojada de potência e efetividade.

Essa hipótese também pode ser assim apresentada: estamos a assistir ao surgimento de uma política mais que institucional, que, por seu ímpeto e por sua forma ultrapassa e compensa a política institucionalizada. Mas, como sempre, um problema se repõe: de que maneira produzir vida coletiva sem fixação institucional, sem regras instituídas? Pode a democracia funcionar efetivamente - como sistema e como valor - sem isso? O puro movimentar-se, a disposição cívica e novas postulações éticas não têm como dar origem a comunidades políticas sustentáveis e capazes de gerar justiça social, igualdade e boas sociedades. Sem regras e instituições que organizem e processem as demandas e os conflitos não se pode ir muito longe. Mas somente com elas corre-se o risco de permanecer girando em falso.

(b) O segundo desafio deriva das pressões identitárias, reveladas ora como recusa à globalização e à ocidentalização, ora como reafirmação religiosa, ora como valorização cultural e simbólica, ora como reiteração étnica, ora enfim como marca pessoal, como identidade pessoal.

A globalização mostra aqui sua ambivalência: ao mesmo tempo em que sufoca tradições culturais e identidades nacionais seculares, ela promove uma espécie de reinvenção radical das identidades, ampliando seu espaço de evidenciação e circulação. Nas condições da modernidade radicalizada, as identidades ficam simultaneamente exacerbadas e com dificuldades de afirmação. O “fundamentalismo” expressa uma importante faceta desse processo, assim como toda uma ampla gama de movimentos de postulação de direitos e de defesa da integridade étnica ou religiosa. As identidades, na verdade, mostram-se de modo multifacetado tanto em seu conteúdo como em sua "forma”. Para empregar a tipologia elaborada por Castells (1998), elas aparecem como identidades legitimadoras, que reiteram as instituições predominantes, identidades de resistência, que expressam postulações de atores "subalternos” preocupados em se proteger, e identidades de projeto, que se estruturam tendo em vista o anúncio de formas novas de vida e de relacionamento. Tais padrões são desiguais em termos de potência e de 
possibilidade, e estão historicamente determinados. Pode-se, porém, sustentar que hoje, instigadas pela sociabilidade contemporânea, por sua dinâmica individualizante e reflexiva tanto quanto por sua efervescência desigual e competitiva, as identidades tendem a se manifestar sobretudo como "resistência”, sem conseguir se traduzir como "projeto”.

Cresce assim o desafio de se continuar a apresentar a democracia como valor universal, submetida a regras procedimentais válidas para todos, a direitos e deveres comuns, a valores compartilhados, a igualdades essenciais. De que modo combinar democracia com etnicidade, com diferenciações religiosas fundamentalistas ou com políticas de identidade muitas vezes particularistas e agressivas? O ideal da comunidade política de todos e aberta a todos cede espaço para lutas corporativistas fechadas em si mesmas, das quais as políticas afirmativas são uma face civilizada e generosa, mas nem por isso menos problemática. Como articular a questão das identidades com o movimento democrático, com os processos de reforma do Estado e do sistema político e com a perspectiva de defesa e valorização de direitos humanos universais? De que maneira recompor a democracia a partir dos novos conflitos, das novas expectativas e dos novos direitos que surgem da hipermodernidade, acolhendo-os como força ativa (tal como no projeto democrático originário) mas sem se entregar inteiramente à particularidade deles?

As questões se desdobram. A postulação e a luta pelo reconhecimento de identidades particulares complicam a dinâmica política nacional, a estabilidade e o funcionamento dos Estados-nação e as próprias identidades nacionais, comprometendo a possibilidade que têm os cidadãos de se reconhecerem como membros de uma mesma comunidade nacional. Se admite que o processo de globalização capitalista e de radicalização da modernidade promove, parcialmente, um “enfraquecimento” do Estadonação, torna-se problemático imaginar a reprodução das identidades nacionais e a sua proteção. Tornam-se mais fluídas e imprecisas as relações entre o Estado e as nacionalidades, bem como o papel das sociedades civis na configuração das experiências sociais concretas, seja em nível nacional, seja em nível mundial. O tema gramsciano da hegemonia, por sua vez, passa a solicitar alguma atualização, dada a impossibilidade material de que ganhem corpo postulações intelectuais, ética e morais abrangentes e unificadoras. A época é de hegemonias imperfeitas, que não se completam.

Dado o entrecruzamento constante das experiências, as sociedades nacionais tornam-se sempre mais "multiculturais", ou melhor, mais segmentadas em espaços culturais particulares que podem (ou não) ser compostos de modo multicultural. O multiculturalismo converte-se assim em projeto de futuro, destinado a diluir o fechamento, a reivindicação de "pureza” e o estranhamento entre as culturas. Fato que seguramente pressiona a democracia. "Num mundo atravessado por intercâmbios culturais intensos, não há democracia sem reconhecimento da diversidade entre as culturas e das relações de dominação que existem entre elas”. Separados um do outro, esses dois aspectos - a diversidade e a dominação 
- se deformam. "A luta de libertação das minorias pode levar a sua comunitarização, ou seja, a sua subordinação a um poder político autoritário. O reconhecimento da diversidade, ao contrário, pode levar a uma autosegregação: cada uma das culturas fecha-se em um território e considera como agressão toda tentativa de comunicação proveniente do exterior”. O projeto multicultural, "longe de romper com o espírito democrático que se baseia no universalismo individualista, é a consumação da idéia democrática como reconhecimento da pluralidade dos interesses, opiniões e valores”. (TOURAINE, 1997: 203).A tradução política desse projeto, no entanto, depende de uma reconfiguração da política.

"Parecemos necessitar de uma nova forma de política, uma política que não encare a afirmação étnica, religiosa, racial, lingüística ou regional como uma irracionalidade arcaica e ingênita, a ser suprimida ou ultrapassada, como uma loucura censurada ou uma escuridão desconhecida, mas que a veja, como a qualquer outro problema social - a desigualdade, digamos, ou o abuso de poder -, como uma realidade a ser enfrentada e modulada, com a qual de algum modo é preciso lidar e chegar a um acordo”. (GEERTZ, 2001: 215).

(c) O terceiro e mais complicado desafio vem, por fim, da dinâmica individualizante, manifestada ora como proclamação de indivíduos autorreferenciados, ora como questionamento e esvaziamento das instâncias institucionalizadas de regulamentação, socialização e normatização, ora ainda como vocalização de novas motivações éticas. Todas essas vertentes impulsionam e fazem crescer um processo social "fora de controle", caótico, ainda que também virtuoso, posto que recusa a unidimensionalidade e problematiza o poder e a autoridade. Soltos de seus grupos de referência e das instituições, os indivíduos mostram-se inseguros e instáveis - flutuantes -, carentes de proteção e de identidades estáveis, confusos e sem utopias. Voltam-se para novas seitas e novas religiões, que recompõem o sagrado e funcionam - de modo mais pragmático e menos institucionalizado (menos hierárquico e mais "participativo")- como um fator de reconhecimento e de pertencimento, ou seja, de identificação coletiva. Mas os indivíduos também agem de modo mais reflexivo, exploram zonas dantes proibidas, diversificam agendas, descobrem novos caminhos e novos modos de fazer coisas, de se relacionar, de organizar, de decidir.

Trata-se de uma cláusula pétrea da moderna interpretação sociológica: a "segunda modernidade” assenta-se sobre a individualização. Em vez de mover-se pelo jogo coletivo dos grandes agregados e dos grupos de referência, agora a sociedade caminha sob o empuxo de homens e mulheres individuais que, com seus próprios recursos (materiais, ideais, cognitivos, emocionais) e sua própria ação, fazem com que coisas aconteçam, ou não. Desigualdades, diferenças e injustiças sociais persistem -ou em condição de estabilidade, ou sendo aprofundadas-, mas não seguem mais parâmetros rigidamente estratificados. A individualização e a diversificação das situações e dos estilos de vida "minam na base o modelo hierárquico das classes e das camadas sociais", projetando a sociedade para "além das 
classes e das estratificações sociais”. A individualização produz indivíduos mais autônomos e mais individualidade, podendo também produzir individualismo. E esses seus produtos convertem-se na "unidade reprodutiva do mundo da vida social”: tanto no interior quanto no exterior da família, os indivíduos "tornam-se os atores da sua existência mediada pelo mercado e pela relativa programação e organização da vida”. (Beck, 2001: 115-118).

As sociedades não podem mais ser pensadas mediante princípios gerais unificadores, na medida em que passam a ser estruturadas a partir da "vontade pessoal de individuação que nos leva a combinar nossa personalidade individual e nossa herança cultural com a participação no mundo das técnicas da economia e da gestão da vida coletiva, para construir nossa experiência de vida pessoal” (Touraine, 1997: 165). Trata-se daquilo que Lipovetsky chamou de processo de "personalização”: um novo modo de a sociedade se organizar e se orientar, um novo modo de gerenciar os comportamentos, "não mais pela tirania dos detalhes, mas com o mínimo de constrangimento e o máximo possível de escolhas privadas, com o mínimo de austeridade e o máximo possível de desejo, com um mínimo de coerção e o máximo possível de compreensão”. (Lipovetsky, 2005: XVII).

Não há propriamente emancipação, como se o indivíduo ressurgido e livre dos grilhões houvesse dado início à “autocriação do mundo” (Beck), até mesmo porque a individualização caminha junto com tendências à institucionalização e padronização das condições de vida, que fazem com que os indivíduos se tornem ainda mais dependentes do mercado, da instrução, do consumo, das políticas dedicadas a gerir o espaço público, e assim por diante. O que ocorre é um aumento da liberdade de movimentação e da autonomia, assim como uma maior abertura e flexibilização das instituições. Passa-se a viver em contextos que se ressentem da "notável ausência de uma agência capaz de mover o mundo para frente": a "fadiga do Estado moderno é talvez sentida de modo mais agudo, pois significa que o poder de estimular as pessoas ao trabalho -o poder de fazer coisas- é tirado da política, que costumava decidir que coisas deveriam ser feitas e quem as deveria fazer” (Bauman, 2001: 153-154).

O individualismo da modernidade radicalizada -o hiper-individualismo- não é necessariamente egoísta e predatório: “Embora não possa ser dissociado da consagração tanto dos gozos privados quanto do mérito individual, é forçoso constatar que, ao mesmo tempo, ele se faz acompanhar de uma multiplicação das exigências de reconhecimento público, de reivindicações de igual respeito às diferentes culturas”. A hipermodernidade "não se esgota no ímpeto solipsista dos apetites consumistas: na realidade, ela traz uma ampliação do ideal do igual respeito, de um desejo de hiperreconhecimento que, recusando todas as formas de desdém, de inferiorização do eu, exige o reconhecimento do outro como igual na diferença”. (Lipovetsky, 2004: 95-96).

Trata-se pois de um individualismo que reforça a democracia em uma 
de suas dimensões mais emblemáticas: a da igual valorização de cada um e de todos. Para se realizar - ou seja, para ser vivida pelos indivíduos como expressão de uma "vida feliz" ou "vantajosa" -, a dinâmica do individualismo impulsiona uma tendência à identificação com o outro, ao reconhecimento do outro. Não implica necessariamente saídas individualistas nem desprezo pelo espaço público, coletivo. Cria novas formas de agregação, novas agendas, novas exigências e reivindicações, uma nova sociabilidade e, portanto, novas expectativas e novas condutas políticas. Por extensão, tende a subverter a política e a pressionar em favor de sua reforma.

"Para além da 'guerra dos deuses' weberiana e do crescente poder da sociedade de mercado, afirma-se um núcleo duro de valores compartilhados que estabelecem limites estreitos ao rolo compressor do raciocínio operacionalista. Nem todo o nosso patrimônio éticopolítico foi erradicado: permanecem válvulas de escape axiológicas que nos impedem de endossar a interpretação radicalista do niilismo hipermoderno”. (Lipovetsky 2004: 99).

Seria possível também associar, a essa posição que dá tratamento positivo à individualização, a perspectiva do indivíduo autonomizado em termos de pensamento, ou seja, capaz de pensar com a própria cabeça, tanto no sentido da colocação em dúvida das informações e opiniões alheias (e também, portanto, dos comandos e orientações governamentais, ou estatais), quanto no sentido da elaboração da própria concepção do mundo e da organização de um quadro de referência para a ação. Ela aponta para a ruptura com padrões instituídos de pensamento e formação de consciências, que refletem, em maior ou menor grau, "imposições" dos grupos sociais "nos quais todos estão automaticamente envolvidos desde sua entrada no mundo consciente", incentivando a que os indivíduos possam "elaborar a própria concepção do mundo de uma maneira consciente e crítica, ser o guia de si mesmo e não mais aceitar do exterior, passiva e servilmente, a marca da própria personalidade”. (Gramsci, Cadernos do cárcere, vol. 1, pp. 93-94).

O hiperindividualismo reforça mas também desafia a democracia: como compor o coletivo - como chegar a sínteses políticas que estruturem e governem um viver coletivo - em meio a tantas postulações plurais e particularistas, que se manifestam num momento de recomposição do capitalismo e de prevalência do mercado? É um desafio que desorganiza e dramatiza a democracia e os próprios territórios sociais. Mas os valores, as orientações e os procedimentos por ele impostos apontam em sentido dominantemente positivo:

"responsabilidade, organização e política autônomas constituem para as pessoas uma chance realista de acolher sem preconceitos, e chegou o momento em que também a política, que por toda parte está se chocando com seus próprios limites, desfrute desses recursos tendo em vista uma nova divisão das responsabilidades e do poder”. (Beck, 2000:51). 


\section{Novos e velhos ativistas}

Impulsionadas por essa dinâmica, as sociedades se tornam cada vez mais parecidas entre si, mas dentro delas a diferença se reproduz incessantemente. Sem centros claros de coordenação, as partes (grupos, indivíduos, regiões) se afastam umas das outras e seguem lógicas próprias - ainda que, paradoxalmente, tudo fique mais conectado. A multidão de novos sujeitos que explode na arena pública e gera novos conflitos não consegue redirecionar o jogo político em termos emancipadores. A hiperatividade da sociedade civil ocorre mais em função da necessidade de autoexpressão que da disposição para entrar no jogo político e organizar consensos.

Com isso, declina a confiança das pessoas nas instituições políticas. Os próprios politicos enredam-se sempre mais nos meios especificos da política, sejam eles a disputa por votos ou a distribuição de verbas e favores. A relação com os negócios agiganta-se. Cresce o risco de corrupção, diminui a densidade ética da política, o debate público democrático tende à superficialidade, ao prosaismo e aos truques mercadológicos. Todos se tornam mais preocupados em gerir recursos de poder e maximizar interesses eleitorais, desistindo de agir para organizar novos consensos e consentimentos. Desajustada pelos novos termos da vida social, a política passa a produzir mais problemas que soluções. Deixa de ser o principal fator de composição social, de processamento de demandas e de modelagem de agendas. Sociedades, indivíduos, grupos, nações e Estados tornam-se partes soltas de um conjunto sem muita articulação sistêmica.

A nova "zona de ação política" que desponta é menos institucional e mais individualizada, mais dinâmica e menos estruturada. Cria a plataforma de uma nova politicidade, cujo teor e formato institucional ainda estão por ser estabelecidos.

Emergem assim novas formas de engajamento e ativismo, que incorporam antes de tudo as novas gerações (os jovens), mas não se resumem a elas, já que tendem a crescer como uma espécie de paradigma da ação política. Sua característica essencial é o questionamento do ativismo tradicional, sustentado por organizações hierarquizadas, classes sociais e causas gerais. O novo ativista luta por direitos e reconhecimento, não por poder. Não sacrifica a vida pessoal em nome de uma causa coletiva ou da glória de uma organização. Não se referencia por líderes ou ideologias. Age festivamente e sem rotinas fixas, valendo-se muitas vezes da sátira e do deboche. É multifocal, abraça várias causas simultaneamente. Sua mobilização é intermitente. Muitos atuam de modo pragmático, profissionalizam-se como voluntários, buscam resultados mais do que confrontação sistêmica. Seu ambiente são as redes sociais, sua maior ferramenta é a conectividade.

Não há, porém, muralhas intransponíveis separando velhas e novas formas de ativismo, que se cruzam e podem se combinar de diferentes 
maneiras, beneficiandose reciprocamente. Se suas agendas contém distintas ênfases e questões, tambem estão repletas de temas que somente podem ser enfrentados com sucesso se se interpenetrarem e forem articulados em uma plataforma de síntese politica.

O novo ativismo pode ser uma importante alavanca de construção do futuro. Será isso, no entanto, na medida em que considerar o conjunto da experiência social e convergir para a reforma democrática da sociedade, do Estado e da politica. Se tentar evoluir solitariamente, fechado em suas causas específicas e na busca de autoexpressão, só produzirá ruído e efervescência, perdendo em termos de efetividade.

A necessidade dessa articulação está posta pela vida. Afinal, o social que se fragmenta não desaparece como social, nem a dimensão coletiva da existência se dissolve só porque a individualização se expande. Ainda continua a ser fundamental combinar ações e promover convergências. Além disso, os conflitos de classe permanecem e mantém sua potência contestadora mesmo que as classes não estejam podendo ser atores politicos no sentido próprio do termo. As estruturas de poder, ainda que possam ter enfraquecidos alguns de seus fluxos, preservam sua capacidade de emitir ordens, pressionar e coagir.

O circuito da hegemonia - que fixa as orientações de sentido e a direção intelectual e moral de grupos e indivíduos - não deixa de existir em condições de “vida líquida”. Ao contrário, fica simultaneamente turbinado e dramatizado. Turbinado porque as ideologias dominantes são potencializadas pelos novos termos do jogo social: ao ganhar preponderância sobre o Estado e se globalizar, o mercado se converte, ele próprio, em cultura política e passa a modelar mentes e condutas com seus valores. Torna-se, por assim dizer, base material e usina de uma hegemonia de tipo sistêmico que, ao se reproduzir, rouba energia e vigor persuasivo das propostas hegemônicas alternativas. Mas essa hegemonia é igualmente incompleta e não traz consigo nenhuma fantasia coletiva.

O circuito da hegemonia fica dramatizado porque é afetado pela revolução informacional-comunicacional e pela dinâmica das redes. O modo prevalecente de pensar, de produzir conhecimentos, de estudar, discutir, assimilar e usar informações faz com que um turbilhão incessantemente expandido de ideias se projete na esfera pública e embaralhe as cartas das lutas por hegemonia. Perdem-se os focos e os núcleos que forneciam condições de unificação das opiniões e da formação de consensos, que passam agora a nascer de forma espasmódica, intermitente, flutuante processo que evidentemente prejudica muito mais as forças de contestação do que as forças da ordem. Ao menos parte dessas últimas chega mesmo a se beneficiar com o novo contexto, que lhes concede espaços e fontes inconscientes de legitimação (mediante, por exemplo, a reação de indignação, decepção ou rebeldia diante de políticas governamentais progressistas ainda não plenamente rotinizadas; ou então mediante o enorme e caótico conjunto de juízos e “verdades” que emerge do frenesi dialógico das redes). Já as 
forças de contestação perdem consensos e condições de ação unificada em decorrência da própria pluralidade político-ideológica posta em marcha pela revolução informacional e da perda de centralidade dos fatores materiais e subjetivos que fizeram sua fortuna no ciclo histórico anterior: a indústria, a fábrica, a classe operária, o Wefare State, os sindicatos, os partidos políticos.

\section{Conclusao}

A flutuação hipermoderna das instituições faz com que haja pouco balizamento institucional das condutas individuais, dos relacionamentos, da dinâmica econômico-financeira, das relações com a natureza. O processo de “desinstitucionalização” abala e tumultua a vida social, mesmo que venha acompanhado de novas instituições, que despontam a partir dos escombros das antigas. Os indivíduos estão obrigados a ser “autônomos”, ainda que não estejam propriamente emancipados. Recebem poucas orientações de sentido provenientes do social, que para eles aparece como palco de um drama sem roteiro. As pessoas precisam e querem se mexer, circular, fazer coisas, dizer o que pensam e batalhar pelo que acham certo. Freqüentam sempre mais o ciberespaço, interagem à distância, têm de se expor e decidir. Mesmo que esse estilo de vida não seja compartilhado por todos, a dinâmica por ele gerada influencia tudo. Sobra menos tempo, menos energia e menos condições materiais para que se criem e se cuidem de instituições. As pessoas escapam das instituições, não se reconhecem nelas.

Não é por outro motivo que as instituições representativas têm menos prestígio que a idéia e as experiências de participação. No mundo social fragmentado, individualizado e meio fora de controle em que se vive, é muito mais lógico participar e defender interesses do que se fazer representar. A vontade de participar -de "agir", de se "movimentar"- tem a cara da modernidade turbinada dos dias atuais.

É na estrada da participação que estão as maiores esperanças de recomposição social e recuperação da política. Se a vontade de participar for devidamente politizada -isto é, se a luta em defesa de direitos e a disposição participativa das pessoas forem vinculadas a um desenho de vida coletiva - isso não somente dará corpo e consistência à democracia, como também revigorará a representação. Não se trata de pôr em curso novas experiências de "gestão participativa” ou de "orçamento participativo”, fórmulas que hoje não conseguem mais produzir frutos renovadores. Será preciso experimentar sucessivas reformas políticas que ajustem e remodelem as instituições políticas, tornando-as mais coerentes, mais eficazes e mais dialógicas com a vida real do século XXI. Mas será igualmente decisivo descobrir como abrir mais espaços para a projeção das pessoas na política.

A situação é ambivalente: repleta de crises, riscos, perigos e oportunidades, de novas armadilhas cerceadoras e de muito mais autonomia. Por 
vias tortuosas, em meio a dor, caos, injustiça e confusão, a democratização continua a avançar. $\mathrm{O}$ novo ativismo ajuda a que o conflito social se reponha de acordo com os novos termos do jogo social. Traz consigo, no entanto, uma dúvida quanto à sua eficácia: quem unifica as múltiplas agendas e os múltiplos focos de reivindicação? Seu eixo também fica problematizado. Do que se trata, de construir ou de destruir, de lutar por um amanhã melhor (como se fazia antes) ou de tentar impedir que o amanhã não seja pior do que o hoje?

Está aberta a discussão para que se encontrem os meios de pôr em curso uma prática cotidiana que invada as instituições mas seja maior que elas e, sobretudo, não seja indiferente a elas; que promova a reunião do social — seus movimentos e seus conteúdos "programáticos" - e do institucional, dando outra qualidade à política como poder, administração e decisão. Isso certamente significa facilitar as ações de desmascaramento, dedicadas a desnudar o cinismo, as mentiras, as injustiças, a arrogância dos poderosos, a frieza dos tecnocratas. Mas significa mais ainda impregnar a política de cultura, fundando outra ideia de Estado, de progresso, de sociedade.

Trata-se, pois, de retomar a política em outra chave e em um patamar superior: reformar suas instituições e reinventá-la como prática e como cultura. Significa “deixar” as pessoas fazerem política, repolitizando a vida, as atividades, o modo de pensar. Não para que assumam a condição de políticos profissionais, mas para que possam atuar para fazer com que as questões essenciais e os valores socialmente instituídos prevaleçam no debate político e nas ações do Estado, de maneira a que se criem novos parâmetros coletivos. Com isso, pode-se acelerar o pleno delineamento de uma democracia representativa sintonizada com os novos tempos, ou seja, com sociedades de massas expandidas, individualizadas, submetidas à globalização e à proliferação de redes e sistemas de comunicação intensiva. Será de pouca serventia um ativismo cívico que complete a demolição da democracia representativa sem nos dizer como substituir ou reformar a representação e como impedir que a participação se converta numa imposição das partes ao todo.

Apolítica continua revestida da capacidade de criar a dose de "sentido comum” necessária para que se costurem os interesses e valores particulares uns nos outros, superando-os a partir de alguma equivalência superior e do incremento de sua capacidade de agir sobre o mundo. Sem política, não há como ultrapassar a explicitação segmentada das demandas sociais e individuais e aproveitar o que existe, nessa explicitação e nas próprias demandas, de energia produtora de vida comunitária. 


\section{Bibliografía}

Bauman, Z. (2001), Modernidade líquida. Zahar, Rio de Janeiro.

Beck, U. (2003), Liberdade ou capitalismo? Editora UNESP, São Paulo.

Ídem (2000), I rischi della libertà. L'individuo nell'epoca della globalizzazione. Il Mulino, Bolonha.

Ídem (2001), La società del rischio. Verso una seconda modernità. Carocci Editore, Roma.

Castells, M. (1999), O poder da identidade. Paz e Terra, São Paulo.

Geertz, C. (2001), "O mundo em pedaços: cultura e política no fim do século”. In Idem, Nova luz sobre a antropologia. Zahar, Rio de Janeiro, p.191-228.

Gramsci, A. (2000), Cadernos do cárcere, vol. 1. Civilização Brasileira, Rio de Janeiro.

Lipovetsky, G. (2004), Os tempos hipermodernos. Editora Barcarolla, São Paulo.

Ídem (2005), A era do vazio. Ensaios sobre o individualismo contemporâneo. Manole, São Paulo.

Nogueira, M.A. (2001), Em defesa da política. $2^{\text {a }}$ ed. Editora Senac, 2005,São Paulo.

Touraine, A. (1997), Podremos vivir juntos? Fondo de Cultura Económica, Buenos Aires.

Ídem (2006), Um novo paradigma. Para compreender o mundo de hoje. $2^{\text {a }}$ ed. Vozes, Petrópolis.

Recibido: 18.11.2013

Aceptado: 28.02.2014 